\title{
Prevalence and Antibiotic Susceptibility of Escherichia Coli Isolated from Meat-Based Products in Port-Said Markets
}

\author{
Eid H. M., El-Tabiy A. A. ", and Fathy S. M. \\ Department of Bacteriology, Immunology and Mycology, Fac. Vet. Med. \\ Suez Canal University, *Animal Health research institute, Port-Said branch.
}

\begin{abstract}
Eight hundred of meat products were collected randomly from PortSaid markets for $E$. coli isolation that was (43\%). E. coli was recorded in $(19.77 \%)$ minced meat, $(17.44 \%)$ in raw meat, $(17.15 \%)$ in sausage, $(16.57 \%)$ in burger, $(15.70 \%)$ in pastirma, $(6.10 \%)$ in luncheon, $(4.07 \%)$ in salami, and $(3.20 \%)$ in frankfurter. Serologically, E. coli isolates were categorized into the following serotypes: $(\mathrm{O} 25, \mathrm{O} 26$, O55, O63, O78, O86, O111, O112, O114, O119, O124, O125, O126, O136, O142, O157, O158), and un-typed serotypes. Antibiotic sensitivity test revealed that all isolates were sensitive to Imipenem, Chloramphenicol, Nalidixic acid, and Ofloxacin while they were resistant to Erythromycin, Penicillin, Bacteracin, Cephradin, Rifampin, Tetracycline, Ciprofloxacin, and Vancomycin.
\end{abstract}

\section{Introduction}

Escherichia coli is Gram-negative rod-shaped bacterium Gansheroff and O'Brien (2000) that its presence in beef carcasses during processing considered as an indicator of fecal contamination Rantsiou et al. (2012). There are over 170 known serogroups of E. coli, classified according to somatic (O), flagellar $(\mathrm{H})$, and/or capsular $(\mathrm{K})$ antigens Wong et al. (2000).

E. coli antibiotic resistance is of a particular concern because it is the most common Gram-negative pathogen in humans, the most common cause of urinary tract infections, a common cause of both community and hospital-acquired bacteremia Salvadori et al. (2004) and a cause of diarrhea Kaper et al. (2004). Because of resistance to most first-line of antibiotics, treatment of E. coli infection became complicated Sabaté et al. (2008).

Therefore, this study aimed to study prevalence, serotyping, and antibiotic sensitivity of $E$. coli isolated from meat and meat-based products.

\section{Material and Methods}

Sample collection: Eight hundred samples consisted of 100 raw meat samples and 700 raw meat-based products samples included (minced meat, sausage, burger, pastirma, luncheon, salami, frankfurter) were collected from Port Said governorate markets as 100 from each during 
period from September 2016 to September 2018.

Sample preparation: Twenty-five grams of each product represented the product sample added aseptically to $225 \mathrm{ml}$ buffered peptone water then enriched by incubation at $37^{\circ} \mathrm{C}$ for 24 hours ICMSF (1978).

Bacterial isolation: Enriched samples were streaked on Eosin Methylene Blue agar (EMB) and MacConkey's agar and incubated at $37^{\circ} \mathrm{C}$ for 24 hours while on Tryptone Bile Glucuronic Agar (TBX) were incubated first at $37^{\circ} \mathrm{C}$ for 4 hours then at $44^{\circ} \mathrm{C}$ for 20 hours Koneman et al. (1997).

Serological examination: Isolates were submitted to serological typing by slide agglutination test using $\mathrm{O}$ somatic antigens Edwards and Ewing (1972).

Antibiotic sensitivity test: Antibiotic sensitivity test was done by disc diffusion test Bauer et al., (1966) and isolates were classified as sensitive, intermediate, or resistant according to NCCLS/CLSI (2007).

\section{Results and Discussion}

Meat and meat products are highly susceptible to microbial contamination as they are rich in essential nutrients Dave and Ghaly (2011). E. coli colonies exhibited unique metallic green sheen on EMB agar plate Figure (1), blue green on TBX agar Figure (2), and lactosefermenting pink colonies on MacConkey's agar Figure (3) that go parallel with Omoruyi et al.
(2018), Verhaegen, et al. (2015), and Abd El Tawab et al. (2015) respectively. The typical biochemical responses of $E$. coli listed in Table (1) were in line with Tafida et al. (2014).

The prevalence of E. coli in examined raw meat and meat based products samples was $344 / 800$ (43\%) which is nearly similar to $\boldsymbol{E l}$ Sharkaway et al. (2016) who reported E. coli as $(41 \%)$. High rate of $E$. coli can be attributed to high initial contamination in slaughterhouses, fecal contamination of carcass during dressing, contamination during products preparation by using raw materials with poor quality, contamination via workers, contaminated working surfaces, contaminated instruments, inappropriate transportation and refrigeration conditions. Results listed in Table (2) illustrated E. coli prevalence in each meat product. The present results is lower than ElSharkaway et al. (2016) as they recorded E. coli highest ratio in burger as $(29.26 \%)$ followed by minced meat as $(26.82 \%)$, sausage as $(24.39 \%)$, and pastirma as (19.51\%).

The most predominant serotype was $\mathrm{O} 125$ as (25\%) followed by $\mathrm{O} 158$ as (20.93\%), un-typed serotypes as (12.5\%), O111 as (10.47\%), O55 as $(8.43 \%), \mathrm{O} 157$ as $(5.81 \%), \mathrm{O} 26$ as (4.07\%), $\mathrm{O} 119$ as $(2.33 \%), \mathrm{O} 142$ as $(2.03 \%), 0114$ as $(1.74 \%)$, both $\mathrm{O} 124$ and $\mathrm{O} 136$ as $(1.45 \%), \mathrm{O} 78$ as (1.16\%), O112 as (0.87\%), both O63 
and $\mathrm{O} 126$ as $(0.58 \%)$, and both $\mathrm{O} 25$ and $\mathrm{O} 86$ as (0.29\%). Ibrahim et al. (2015) isolated similar E. coli serotypes from meat products as O26, O55, O111, O114, O119, $\mathrm{O} 124$, and $\mathrm{O} 125$.

Antibiogram of E. coli listed in Table (3) and Figure (4) revealed that $(95.93 \%)$ of isolates were highly sensitive to Imipenem which is in agreement with Gundogan and Avci (2013). About (94\%) of isolates were highly sensitive to Chloramphenicol which goes parallel with Oja et al. (2010). Also, (74.13\%) of isolates were sensitive to Nalidixic acid which is nearly similar to Nobili et al. (2017) who confirmed that all tested E. coli isolates were sensitive to Nalidixic acid. Moreover, none of E. coli isolates were resistant to Ofloxacin as $(77.03 \%)$ were highly sensitive while $(22.97 \%)$ were moderately sensitive to it.

In addition, $(85.76 \%)$ of isolates were moderately sensitive to Neomycin while $(2.91 \%)$ were sensitive to it. Rahman et al. (2017) recorded higher sensitivity rate, as all $E$. coli isolates were sensitive to Neomycin. Arya et al. (2008) reported that only (20\%) of $E$. coli isolates were sensitive to Amikacin which is lower than the current result as $(40.12 \%)$ were sensitive to Amikacin.

Furthermore, Srinivasa et al. (2011) illustrated that $(10.7 \%)$ of $E$. coli isolates were resistant to Polymyxin
B which is nearly similar to the present study as $(8.72 \%)$ of E. coli isolates were resistant to Polymyxin B. Rahman et al. (2017) detected that $(28.57 \%)$ of $E$. coli isolates were resistant to Doxycyclin which is higher than the present study as $(17.15 \%)$ of isolates were resistant to Doxycyclin.

In addition, (51.45\%) of isolates were intermediately sensitive to Amoxicillin/Clavulanic acid and $(31.40 \%)$ of isolates were resistant to it. Higher resistance rate recorded by Ammar et al. (2016) as (93.75\%) of isolates were resistant. About (40\%) $E$. coli isolates were resistant to Trimethoprim/Sulfamethoxazole but lower resistance rate as $(28.57 \%)$ recorded by Rahman et al. (2017).

Present result demonstrated resistance of isolated $E$. coli serotypes to Erythromycin that agrees with Al-Sultan et al. (2012). This may be resulted from long-term and widespread abuse of Erythromycin in livestock fields. All $E$. coli isolates were resistant to Bacitracin, Vancomycin Nicoline et al. (2015) and Tetracycline Anu and Gayathri (2015) which agree with present result. Ciprofloxacin resistance was $(100 \%)$ which is higher than Yang et al. (2004) who recorded Ciprofloxacin resistance as $(84 \%)$. All E. coli isolates $(100 \%)$ were resistant to Penicillin G. Last researches described Penicillin as non-effective antibiotic against $E$. coli Kundu et al. (2019) 
Table (1): Biochemical reactions of E. coli isolates

\begin{tabular}{|l|c|}
\hline \multicolumn{1}{|c|}{ Biochemical Tests } & E. coli \\
\hline Gram stain & Gram Negative bacilli \\
\hline Oxidase test & - \\
\hline Catalase test & + \\
\hline Indole test & + \\
\hline Methyl Red test & - \\
\hline Voges-Proskauer test & - \\
\hline H2S production on TSI & Yellow color with acid production \\
\hline On TSI "slant" & Yellow color, acid, and gas production \\
\hline On TSI “butt" & - \\
\hline Citrate test & - \\
\hline Urease test & + \\
\hline Lactose, Mannitol, Glucose fermentation & Variable \\
\hline Sucrose fermentation & \\
\hline
\end{tabular}

Table (2): Prevalence of E. coli in all raw meat and meat based products samples

\begin{tabular}{|l|c|c|}
\hline Meat and meat products & No. of $\boldsymbol{E}$. coli isolates & \%* \\
\hline Pastirma & 54 & 15.70 \\
\hline Minced meat & 68 & 19.77 \\
\hline Frankfurter & 11 & 3.20 \\
\hline Burger & 57 & 16.57 \\
\hline Sausage & 59 & 17.15 \\
\hline Luncheon & 21 & 6.10 \\
\hline Raw meat & 60 & 17.44 \\
\hline Salami & 14 & 4.07 \\
\hline Total & 344 & 100 \\
\hline
\end{tabular}

$*(\%)$ calculated according to total no. of $E$. coli isolates $=344$ 
Table (3): Antibiogram of E. coli isolates.

\begin{tabular}{|c|c|c|c|c|c|c|}
\hline \multirow{3}{*}{ Antimicrobial agent } & \multicolumn{6}{|c|}{ E. $\operatorname{coli}($ No. $=344)$} \\
\hline & \multicolumn{2}{|c|}{ Sensitive } & \multicolumn{2}{|c|}{ Intermediate } & \multicolumn{2}{|c|}{ Resistant } \\
\hline & No. & $\% *$ & No. & $\% *$ & No. & $\% *$ \\
\hline Doxycyclin $(30 \mu g)$ & 0 & 0.00 & 285 & 82.85 & 09 & 17.15 \\
\hline Nalidixic acid $(30 \mu \mathrm{g})$ & 255 & 74.13 & 59 & $1 V, 10$ & 30 & 8.72 \\
\hline Neomycin $(30 \mu g)$ & 10 & 2.91 & 295 & 85.76 & 39 & 11.34 \\
\hline Rifampin $(5 \mu \mathrm{g})$ & 0 & 0.00 & 0 & 0.00 & 344 & 100 \\
\hline Chloramphenicol $(30 \mu \mathrm{g})$ & 324 & 94.19 & 10 & 2.91 & 10 & $r, q 1$ \\
\hline Tobramycin $(10 \mu \mathrm{g})$ & 0 & 0.00 & 344 & 100 & 0 & 0.00 \\
\hline Ofloxacin $(5 \mu \mathrm{g})$ & 265 & 77.03 & 79 & 22.97 & 0 & 0.00 \\
\hline Erythromycin $(15 \mu \mathrm{g})$ & 0 & 0.00 & 0 & 0.00 & 344 & 100 \\
\hline Penicillin $(10 \mu g)$ & 0 & 0.00 & 0 & 0.00 & 344 & 100 \\
\hline Bacteracin $(10 \mu \mathrm{g})$ & 0 & 0.00 & 0 & 0.00 & 344 & 100 \\
\hline Amikacin $(30 \mu g)$ & 138 & 40.12 & 197 & 57.27 & 9 & 2.62 \\
\hline Trimethoprim/Sulfamethoxazole $(25 \mu \mathrm{g})$ & 91 & 28.49 & 108 & 31.40 & 138 & 40.12 \\
\hline 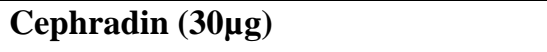 & 0 & 0.00 & 0 & 0.00 & 344 & 100 \\
\hline 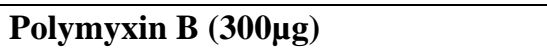 & 0 & 0.00 & TIS & 91.28 & 30 & 8.72 \\
\hline 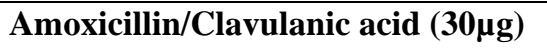 & 59 & 17.15 & IVV & 51.45 & 108 & 31.40 \\
\hline Oxalinic acid $(2 \mu \mathrm{g})$ & 167 & 48.55 & 128 & 37.21 & 49 & 14.24 \\
\hline Vancomycin $(30 \mu \mathrm{g})$ & 0 & 0.00 & 0 & 0.00 & 344 & 100 \\
\hline Ciprofloxacin $(5 \mu \mathrm{g})$ & 0 & 0.00 & 0 & 0.00 & 344 & 100 \\
\hline Imipenem $(10 \mu g)$ & ru. & 95.93 & $1 \leq$ & 4.07 & 0 & 0.00 \\
\hline Tetracycline $(30 \mu \mathrm{g})$ & 0 & 0.00 & 0 & 0.00 & 344 & 100 \\
\hline
\end{tabular}

$*(\%)$ calculated according to total no. of $E$. coli isolates $=344$. 


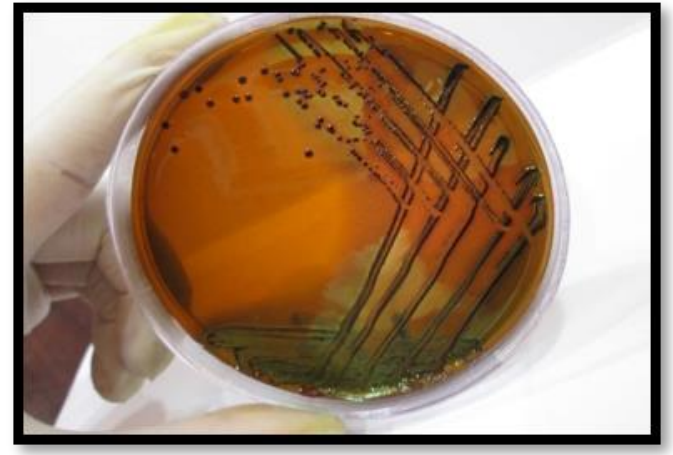

Figure (1): $E$. coli colonies on EMB.

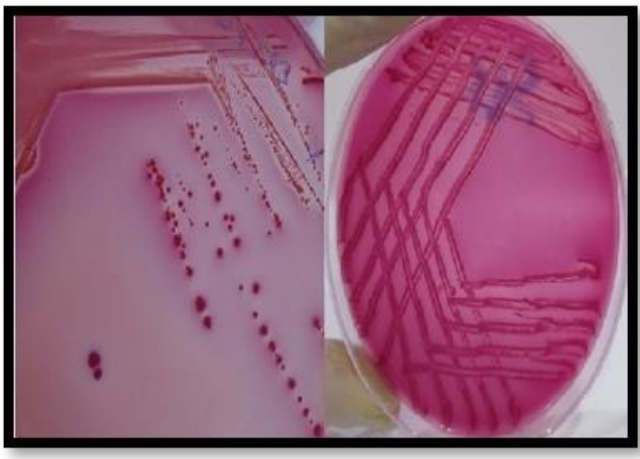

Figure (3) $E$. coli colonies o MacConkey's.

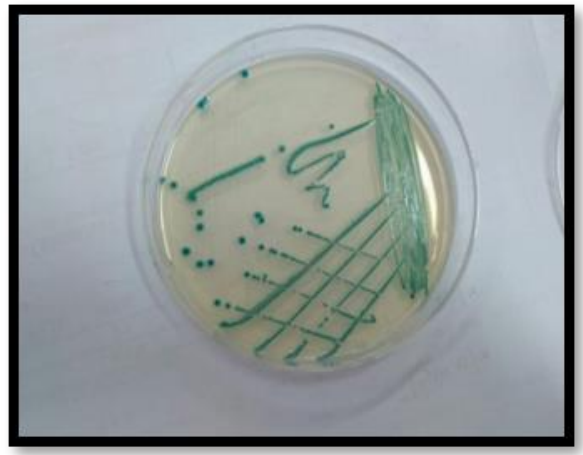

Figure (2): $E$. coli colonies on TBX.

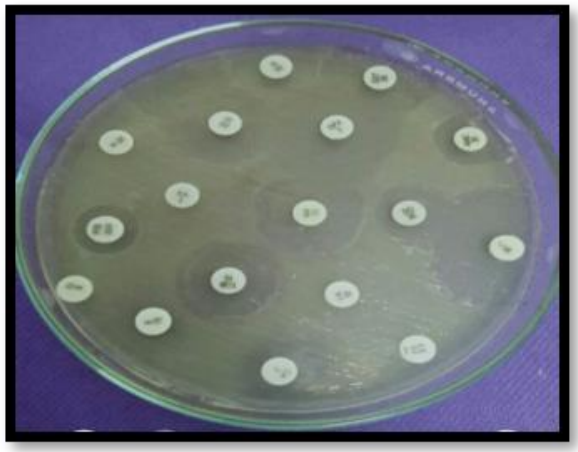

Figure (4): E. coli antibiogram.

\section{Refrences}

Abd El-Tawab, A. A.; El-Hofy, F. I.; Nada, S. M. and Deiab, R. A. A. (2015): Detection of virulence genes of enterohaemorrhagic E. coli isolated from some meat products by polymerase chain reaction Benha Veterinary Medical Journal, Vol. 29, No. 1:45-52, September, 2015.

Al-Sultan, I. I. A.; Jasbir, S. and Fazlina, F. (2012): Antibiotic sensitivity of pathogenic bacteria isolated from beef samples obtained from Kota Bharu and its surrounding provinces. Journal of Advanced Medical Research 2: 8-11.

Ammar, A. M.; Attia, A. M.; Abd El-Aziz, N. K.; Abd El-Hamid, M. I. and El-Demerdash, A. S. (2016): Class 1 integron and associated gene cassettes mediating multiple-drug resistance in some food borne pathogens.

Anu, S. A. and Gayathri, T. (2015): Isolation and characterization of microoragnisms from raw meat obtained fromdifferent market placesinand 
aroundChennai. J Pharm Chem Biol Sci, June-August 2015; 3(2):295-301.

Arya, G.; Roy, A.; Choudhary, V.; Yadav, M. M. and Joshi, C. G. (2008): Serogroups, atypical biochemical characters, colicinogeny and antibiotic resistance pattern of shiga toxin-producing Escherichia coli isolated from diarrhoeic calves in Gujarat, India. Zoonoses and Public Health 55: 89-98.

Bauer, A. W.; Kirby, W. M.; Sherris, J. C. and Turck, M. (1966): "Antibiotic susceptibility testing by a standardized single disk method". Am. J. Clin. Pathol. 45. 493-496. 1966.

Dave, D. and Ghaly, A. E. (2011): Meat spoilage mechanisms and preservation techniques: a critical review. American Journal of Agricultural and Biological Sciences, 6(4): 486-510.

Edwards, P. R. and Ewing, W. H. (1972): Identification of Enterobactericeae. Burgess publ. Co. Minnecepolis. Minnesota; 103-104.

El-Sharkaway, M. S.; Samaha, I. A. and Abd El Galil H. I. (2016): Prevalence of pathogenic microorganisms in raw meat products from retail outlets in Alexandria province. Alexandria Journal of Veterinary Sciences 2016, Nov. 51: 374-380.

Gansheroff, L. J. and O'Brien, A. D. (2000): Escherichia coli O157:H7 in beef cattle presented for slaughter in the U.S.: Higher prevalence rates than previously estimated. Proceedings of the National Academy of Sciences of the United States of America. 2000; 97:2959-2961.

Gundogan, N. and Avci, E. (2013): Prevalence and antibiotic resistance of extended spectrum beta lactamse (ESBL) producing E. coli and Klebsiella species isolated from foods of animal origin in Turkey. African Journal of Microbiology Research. Vol. 7(31), pp. 4059-4064, 2 August, 2013.

Ibrahim, H. M.; Hassan, M. A.; Amin, R. A.; Eleiwa, N. Z. and Nadim, S. S. (2015): Prevalence of E. coli and detection of virulent genes by multiplex PCR in meat products. Benha Veterinary Medical Journal, Vol. 29(2): 268273, December, 2015.

ICMSF (1978): International Commission of Microbiological Specification for Foods. Microorganisms in food 2 Sampling for microbiological analysis: principles and specific applications. Second edition.

Kaper, J. B.; Nataro J. P. and Mobley, H. L. T. (2004): Pathogenic Escherichia coli. Nat. Rev. Microbiol., 2: 123-140.

Koneman, E. W.; Allan, S. D.; Janda, W. M.; Schreckenberger, P. C. and Winn, W. C. (1997): Color atlas and textbook of diagnostic microbiology. $5^{\text {th }}$ Ed. J.B. Lippincoot Company, 1296-1395.

Kundu, D.; Paul, T.; Barkalita L. M. and Borah P. (2019): Virulence gene profile of Escherichia Coli isolated from raw milk and market meat in 
Guwahati City of Assam. Acta Scientific Microbiology (2): 44-49.

NCCLS/CLSI (2007): National Committee for Clinical Laboratory Standards/ Clinical and Laboratory Standards Institute. CLSI document GP 18-Laboratory design; approved guideline. $2^{\text {nd }}$ ed. Clinical and Laboratory Standards Institute, Wayne (PA); 2007.

Nicoline, F. T.; Eunice, S.; Roland, N. N. and Pascal, O. B. (2015): Detection of pathogenic E. coli and Staphylococcus aureus from cattle and pigs slaughtered in abattoirs in Vhembe District, South Africa. The Scientific World Journal volume 2015, Article ID 195972, 8 pages.

Nobili, G.; Ilenia, F.; Gianfranco, L. B.; Maria, G. B. and Giovanna L. S. (2017): Prevalence of Verocytotoxigenic Escherichia coli strains isolated from raw beef in southern Italy. International Journal of Food Microbiology 257 (2017) 201-205.

Oja, O. E.; Ajuwape, A. T.; Otesile, E. B.; Owoade, A. A.; Oyekunle, M. A. and Adetosoye, A. I. (2010): Potentially zoonotic Shiga toxin-producing Escherichia coli serogroups in the feces and meat of food-producing animals in Ibadan, Nigeria. International Journal of Food Microbiology, 142, 214-221.

Omoruyi, I. M.; Uwadiae, E.; Gospel, M. G. and Omoruku, E. (2018): Shiga Toxin Producing Strains of Escherichia coli (STEC) Associated with Beef Products and Its Potential Pathogenic Effect. Microbiology Research Journal International MRJI, 23(1): 1-7, 2018; Article no.MRJI.32959.

Rahman, M. A.; Rahman, A. K. M. A.; Islam, M. A. and Alam, M. M. (2017): Antimicrobial resistance of Escherichia coli isolated from milk, beef and chicken meat in Bangladesh. Bangl. J. Vet. Med. (2017). 15 (2): 141-146.

Rantsiou, K.; Alessandria, V. and Cocolin, L. (2012): Prevalence of shiga toxin producing Escherichia coli in food products of animal origin as determined by molecular methods. International Journal of Food Microbiology. 2012; 154:37-43.

Sabaté, M.; Prats, G.; Moreno, E.; Ballesté, E.; Blanch, A. R. and Andreu, A. (2008): Virulence and antimicrobial resistance profiles among Escherichia coli strains isolated from human and animal wastewater. Res Microbiol. 2008;159: 288-93.

Salvadori, M.; Coleman, B. L.; Louie, M.; McEwen, S. and McGeer, A. (2004): Consumption of antimicrobial-resistant Escherichia coli-contaminated well water: human health impact. PSI Clin Res. 2004;6-25.

Srinivasa, R. T.; Gill, J. P. S.; Ravi, K. G. V. V. P. S. and Sandeep, G. (2011): Multi-drug resistance patterns of shiga toxin producing Escherichia coli (STEC) and non-STEC isolates from meats, RTE meat foods, drinking water and human diarrhoeic samples of Punjab, India. Archives Of Clinical Microbiology. iMedPub Journals 2011 Vol. 2 No. 2:3 doi: 10:3823/225. 
Tafida, S. Y.; Kwaga, J. K. P.; Bello, M.; Kabir, J.; Umoh, V. J.; Yakubu, S. E. and Nok, J. A. (2014): Occurrence of Escherichia coli O157 in Retailed-Beef and Related Meat Products in Zaria, NigeriaFood and Nutrition Sciences, 2014, 5, 481-487.

Verhaegen, B.; Reu, K. D.; Heyndrickx, M. and Zutter, L. D. (2015): Comparison of Six Chromogenic Agar Media for the Isolation of a Broad Variety of Non-O157 Shiga toxin-Producing Escherichia coli (STEC) Serogroups Int. J. Environ. Res. Public Health 2015, 12, 6965-6978; doi:10.3390/ijerph120606965

Wong, C. S.; Jelacic, S.; Habeeb, R. L.; Watkins, S. L. and Tarr, P. I. (2000): The risk of the hemolytic uremic syndrome after antibiotic treatment of Escherichia coli O157:H7 infections. New England Journal of Medicine. 2000; 342:1930-1936.

Yang, H.; Chen, S.; White, D. G.; Zhao, S.; McDermott, P.; Walker, R. and Meng, J. (2004): Characterization of multiple-antimicrobial-resistant Escherichia coli isolates from diseased chickens and swine in China. J. Clin. Microbiol. 42:3483-3489.
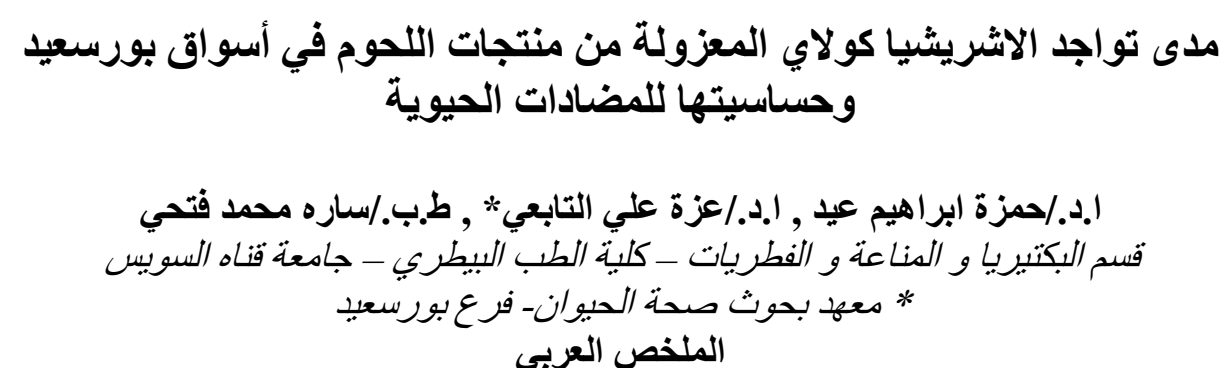
الملخص العربي

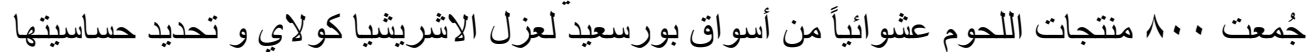

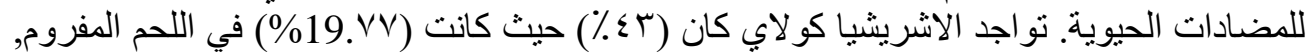

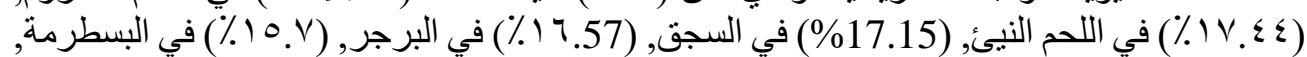

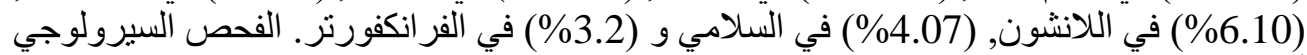

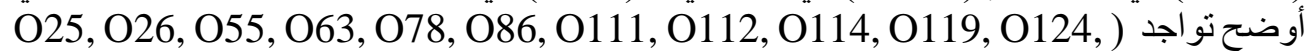

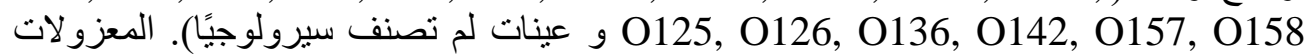

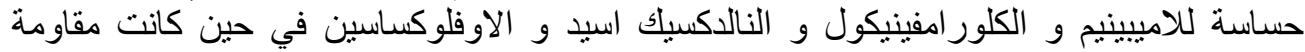

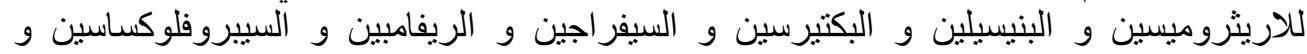
التيتراسيكلين و الفانكوميسين. 